\title{
A FORMAÇÃO PROFISSIONAL DO ENFERMEIRO DOCENTE
}

\section{ARTIGO DE REVISÃO}

MORAES, Rafael Silvério de ${ }^{1}$

MORAES, Rafael Silvério de. A formação profissional do Enfermeiro Docente. Revista Científica Multidisciplinar Núcleo do Conhecimento. Ano 05, Ed. 06, Vol. 12, pp. 72-82. Junho de 2020. ISSN: 2448-0959, Link de acesso: https://www.nucleodoconhecimento.com.br/saude/enfermeiro-docente

\section{RESUMO}

A educação é considerada como um desafio, porque não se resume na transmissão de informações, pois trata-se de um processo de interação entre os sujeitos. docente precisa fazer o reconhecimento das habilidades e limitações dos discentes, focando nas características individuais, e relacionando a história de vida dos sujeitos ao contexto social. Métodos: pesquisa de revisão bibliográfica, que foi realizada na Biblioteca Virtual de Saúde (BVS) com a utilização das palavras chaves: "A formação do Enfermeiro Docente", "Enfermeiro Docente", "Ensino Superior", resultando em 276 publicações compreendidas entre 2006 a 2017 onde selecionou-se 6 publicações para compor a síntese. Resultados: A análise das fontes literárias selecionadas permitiu agrupar as ideias em duas categorias temáticas, sendo elas: 1) Compreender as transformações ocorridas na formação de enfermeiros docentes durante os últimos anos 2) Entender a formação do enfermeiro docente. Conclusão: Seguindo a premissa cientifica do estudo buscou-se apresentar a formação do enfermeiro docente, por meio de revisões bibliográficas foi possível alcançar o objetivo inicialmente proposto desse trabalho. Um ponto de relevância para o estudo foi o fato de observar as transformações ocorridas na formação de enfermeiros docentes durante os últimos

\footnotetext{
${ }^{1}$ Mestrando em Ensino em Saúde - Famema - Marília - São Paulo, pós-graduação em Saúde da Família, pós-graduação em Docência em Enfermagem, pós-graduação em Gestão Escolar, bacharel em Enfermagem, licenciado em Pedagogia.
} 
anos conforme as citações abordadas no trabalho. Faz-se necessário que o docente enfermeiro invista em formação que aborde práticas críticas e reflexivas para que consigo refletir desde sua formação inicial e continuada, na inserção de pesquisas para formação de ações construtivas e críticas.

Palavras-Chave: A formação do enfermeiro docente, enfermeiro docente, Ensino superior.

\section{INTRODUÇÃO}

No Brasil, a formação, o desempenho, o desenvolvimento profissional do docente tem sido como objeto de estudos desde os movimentos que ocasionaram transformações nos cursos superiores. Hoje, é esperado que o docente em nível universitário forme profissionais comprometidos e competentes, a formação do docente em enfermagem deve ser embasado nos domínios de conhecimentos científicos com atuação de investigação no processo de ensino-aprendizagem e valorizando o universo cognitivo (RODRIGUES; SOBRINHO, 2006).

A educação é considerada como um desafio, porque não se resume na transmissão de informações, pois trata-se de um processo de interação entre os sujeitos. $O$ docente precisa fazer o reconhecimento das habilidades e limitações dos discentes, focando nas características individuais, e relacionando a história de vida dos sujeitos ao contexto social (RODRIGUES; MANTOVANI, 2007).

O ensino de enfermagem vem passando por várias mudanças ao longo do seu desenvolvimento, e podemos perceber em cada uma delas o reflexo do contexto social e histórico. Pensar sobre a formação do enfermeiro é uma exigência colocada pela sociedade aos docentes, evidenciando uma nova exigência para graduação em Enfermagem, que gere um profissional preparado para atender as necessidades do século XXI (RODRIGUES; MANTOVANI, 2007).

Na enfermagem percebe-se a necessidade de desenvolver uma política para atuação na docência, tendo que repensar na atribuição do enfermeiro docente e como se 
desenvolve as práticas pedagógicas para atender as novas medidas que a educação determina (PEREIRA; CARDOSO, 2017).

Diante do exposto, percebemos que o mercado de trabalho não admite a presença de profissionais limitados aos seus aspectos profissionais, mas que sejam competentes e preparados para a vida, articulando conhecimentos, com práticas abrangentes, sem desconsiderar dos aprendizados científicos da profissão (RODRIGUES; MANTOVANI, 2007).

No entanto, a prática docente é determinante quanto a formação profissional, e a profissão de docente é mais promissora entre as profissões, porque a sociedade vem aumentando suas demandas de aprendizagem, e os grandes desafios dar-se aos professores que conseguem transformar informações em formação (RODRIGUES; MANTOVANI, 2007).

Aparentemente, o exercício do profissional enfermeiro não coincide a conceitos educativos, assemelha estar junto exclusivamente nos processos gerenciais e de assistência em saúde. No início de seu exercício profissional o enfermeiro tem se aproximado da docência ou consequentemente depois de algum tempo de atuação na assistência, no entanto, existe a necessidade a aprimorar a formação pedagógica dos docentes enfermeiros, com intuito de qualificar o planejamento pedagógico com fortalecimento da teórica com a prática (MORAES, 2004; SOUZA, et al, 2018).

O enfermeiro docente tem como papel de facilitador no processo de ensinoaprendizagem, permitindo aproximação dos discentes da prática profissional, estimulando a construção de conhecimentos, atitudes, habilidades, com responsabilidades e autonomias, contextualizando participação ativa dos discentes (SOUZA, et al, 2018).

Nesse sentido, teve como problema de pesquisa: Como se dá a formação profissional do enfermeiro docente? Em vista disso, abordamos nesse trabalho, a formação do enfermeiro docente em consonância com a ética do exercício profissional. 


\section{MÉTODO}

Trata-se de uma pesquisa de revisão bibliográfica. Esse estado da arte apresenta de forma resumida trabalhos que já foram discutidos por outros pesquisadores que tratam da temática, com levantamento de dúvidas, e críticas quando for necessário (GERHARDT; SILVEIRA, 2009).

A pesquisa foi realizada na Biblioteca Virtual de Saúde (BVS) com a utilização das palavras chaves: "A formação do Enfermeiro Docente", "Enfermeiro Docente", "Ensino Superior", na data 15/08/2018. Após acessar a biblioteca virtual e redigir as palavras chaves, 276 resultados que trabalhavam na mesma linha da minha pesquisa.

Após as leituras dos artigos na integra, foi selecionado dos 276 os 16 que abordassem o objetivo dessa pesquisa. Sendo realizada a leitura completa dos artigos em que foram descartados 10 que não se encaixavam com o objetivo da pesquisa, restando 06, dos quais foram utilizados para o desenvolvimento da mesma.

\section{DESENVOLVIMENTO}

A partir da análise das 06 referências bibliográficas selecionadas, construiu-se o quadro 1 que mostra as informações relativas ao ano, título, autoria e palavras-chave.

Quadro 1. Características das referências bibliográficas da pesquisa, 2006- 2017.

\begin{tabular}{|c|c|c|c|}
\hline \multirow{2}{*}{$\begin{array}{l}\text { ANO DE } \\
\text { REFERÊNCIA }\end{array}$} & \multirow[t]{2}{*}{ TÍTULO } & \multirow[t]{2}{*}{ AUTORES } & PALAVRAS-CHAVE \\
\hline & & & \\
\hline 2006 & $\begin{array}{l}\text { Formação do } \\
\text { enfermeiro: } \\
\text { características do } \\
\text { professor e o sucesso } \\
\text { escolar. }\end{array}$ & $\begin{array}{l}\text { Maria Romana } \\
\text { Friedlander; Maria } \\
\text { Teresa de Arbués } \\
\text { Moreira. }\end{array}$ & $\begin{array}{l}\text { Educação } \\
\text { enfermagem; } \\
\text { Bacharelato } \\
\text { enfermagem; } \\
\text { Docente } \\
\text { enfermagem. }\end{array}$ \\
\hline
\end{tabular}




\begin{tabular}{|c|c|c|c|}
\hline 2008 & $\begin{array}{ll}\text { Os reflexos da } \\
\text { formação inicial na } \\
\text { atuação } & \text { dos } \\
\text { professores } & \\
\text { enfermeiros. } & \end{array}$ & $\begin{array}{l}\text { Marcos Antonio } \\
\text { Ferreira Júnior. }\end{array}$ & $\begin{array}{l}\text { Docente de } \\
\text { enfermagem; } \\
\text { Educação em } \\
\text { enfermagem; Ensino. }\end{array}$ \\
\hline 2010 & $\begin{array}{l}\text { Repensando o ser } \\
\text { enfermeiro docente na } \\
\text { perspectiva do } \\
\text { pensamento } \\
\text { complexo. }\end{array}$ & $\begin{array}{lr}\text { Dirce } & \text { Stein } \\
\text { Backes; } & \text { Mara } \\
\text { Marinho; Regina } \\
\text { Santini } \\
\text { Costenaro; } \\
\text { Simone Nunes; } \\
\text { Irani Rupolo. }\end{array}$ & $\begin{array}{ll}\text { Educação } & \text { em } \\
\text { enfermagem; } & \\
\text { Metodologia; } & \\
\text { Pesquisa } & \text { em } \\
\text { enfermagem. } & \end{array}$ \\
\hline 2013 & $\begin{array}{l}\text { A formação docente e } \\
\text { os desafios da prática } \\
\text { reflexiva. }\end{array}$ & $\begin{array}{l}\text { Maria Regina } \\
\text { Peres, Rogério } \\
\text { Da Costa Ribeiro, } \\
\text { Lisliê Lúcia Lima } \\
\text { Pereira Ribeiro, } \\
\text { Angela Freitas de } \\
\text { Rezende Costa, } \\
\text { Viviane Da Rocha }\end{array}$ & $\begin{array}{l}\text { Prática docente, } \\
\text { Ensino Fundamental, } \\
\text { Formação } \\
\text { docente. }\end{array}$ \\
\hline 2016 & $\begin{array}{l}\text { Satisfação e } \\
\text { sofrimento no trabalho } \\
\text { do enfermeiro } \\
\text { docente: uma revisão } \\
\text { integrativa. }\end{array}$ & $\begin{array}{lr}\text { Carla } & \text { Godinho } \\
\text { Duarte; } & \text { Valéria } \\
\text { Lerch } & \text { Lunardi; } \\
\text { Edison } & \text { Luiz } \\
\text { Devos } & \text { Barlem. }\end{array}$ & $\begin{array}{l}\text { Satisfação no } \\
\text { Emprego; Docentes } \\
\text { de Enfermagem; } \\
\text { Ensino; Educação em } \\
\text { Enfermagem. }\end{array}$ \\
\hline 2017 & $\begin{array}{l}\text { A Formação de } \\
\text { professores e os } \\
\text { desafios de ensinar } \\
\text { Ciências. }\end{array}$ & $\begin{array}{lr}\text { Rita } & \text { Helena } \\
\text { Moreira } & \text { Seixas; } \\
\text { Luciana } & \text { Calabró; } \\
\text { Diogo } & \text { Onofre } \\
\text { Sousa. } & \end{array}$ & $\begin{array}{l}\text { Formação de } \\
\text { professores; } \\
\text { Ciências; } \\
\text { Conhecimento } \\
\text { científico }\end{array}$ \\
\hline
\end{tabular}


Fonte: Elaboração própria dos autores, 2018.

As escolas superiores de enfermagem em Portugal são avaliadas periodicamente, desde o curso a escola, pois o Ministério da Ciência, Tecnologia e Ensino superior exige o levantamento de dados sobre a avaliação do curso, e a escola precisa levantar dados referentes as opiniões dos discentes quanto aos docentes, no entanto, a escola por decisões próprias podem adotar avaliações dos serviços prestados para a sociedade, incluindo também dados referentes aos docentes (FRIEDLANDER; MOREIRA, 2006).

De acordo com o exposto, podemos compreender que o ministério e a instituição de ensino consideram que o docente seja um dos mais importantes instrumento de formação implementado pelas escolas de enfermagem, e que a avaliação está interligada na qualidade de ensino (FRIEDLANDER; MOREIRA, 2006).

Teoricamente a educação formal em enfermagem inseri sobre a ação de um ser humano sobre o outro, docente e o aprendiz, em que o primeiro formaliza todo o aprendizado e o segundo pela ciência e arte da enfermagem se prepara para o desenvolver a profissão (FRIEDLANDER; MOREIRA, 2006).

De acordo com alguns investigadores existem variáveis relacionadas ao docente de enfermagem, como: o conhecimento da disciplina, os métodos pedagógicos, o processo ensino-aprendizagem, e as práticas relacionadas ao ensino (FRIEDLANDER; MOREIRA, 2006).

No Brasil a formação de profissionais para a área da saúde, vem sendo historicamente influenciado pelas variadas técnicas assistenciais, por abordagens conservadoras e fragmentadas, sendo pautadas ao modelo biomédico e curativo, com detrimento as práticas proativas de proteção e promoção de saúde (BACKES, et al, 2010).

Em questão a transmissão de conhecimentos estavam centradas em aulas expositivas, em que o discente era totalmente ou parcialmente facultativo na inserção e participação, por meio de um ensino-aprendizagem focado no docente e na sala de aula, com poucas chances de problematização. Nessa direção de ensino- 
aprendizagem, ocorre restrições de conhecimentos, em que se criam papéis, sendo o docente como transmissor e o discente como receptor dos conteúdos. (BACKES, et al, 2010).

Esse modelo tradicional de ensino vem sendo questionado e transformado por novos referenciais que permitem a ampliação da atuação profissional por meio de pensamentos complexos que possibilitam a construção de aprendizado por caráter circular e dinâmico, pelo fato de não se limitar à somatória dos conteúdos programáticos, mas concretizando a causalidade problematizadora e reflexiva. Esse pensamento vem sustentando a mudança de uma consciência ingênua para uma de abordagem crítica, considerando as múltiplas transformações de relações (BACKES, et al, 2010).

Nessa perspectiva, há necessidade e elaborar um pensamento capaz de desenvolver a autonomia dos indivíduos como seres pensantes e reflexivos, realizando a lógica entre objeto e sujeito (BACKES, et al, 2010).

Portanto, quando o profissional é prático e reflexivo, ele consegue superar as rotinizações de suas ações, refletindo sobre as mesmas antes, durante e após de executá-las, ao se depararem com situações de incertezas, contextualizadas e únicas, esses recorrem para uma investigação que seja capaz de decidir e intervir (PERES, et al, 2013).

As atividades-atribuições do enfermeiro docente ir além de habilidades técnicoscientificas, desenvolvendo habilidades integradoras, inovadoras, interativas, compreendendo os saberes dos discentes e articular os saberes teórico-práticos (BACKES, et al, 2010).

De acordo com um estudo realizado por Júnior (2008) em um grupo de professores (enfermeiros bacharéis e licenciados), percebeu-se que a formação inicial dos docentes tratava-se de acordo com o modelo vigente, previsto pela LDB 9394/6 e proposto pelas Diretrizes Nacionais Curriculares (DCN's) dos cursos de graduação 
em enfermagem, que evidenciam a formação em enfermagem assistencialista (Júnior, 2008).

Contudo, os cursos de graduação em enfermagem estão normalmente interligados a ciências naturais, biológicas e da saúde, influenciados também pelas ciências sociais e humana, sendo seu objeto no cuidado e caracterizando o homem como um ser psicossocial e cultural (Júnior, 2008).

Quando se trata da formação do enfermeiro em modelos bacharéis, percebe-se uma formação preocupada e voltada para assistência em saúde e nas suas diversas áreas, abrangendo saúde coletiva e hospitalar. Entretanto, podemos perceber a falta de formar enfermeiros capacitados para atuarem na docência, pois nos últimos anos essa área vem abrindo espaço devido ao aumento de escolas de enfermagem em nível técnico no Brasil (Júnior, 2008).

A licenciatura em enfermagem, que é uma formação complementar à graduação, com vistas ao preparo para a docência em cursos de nível médio e profissionalizante, apesar de existir já há algum tempo, apenas recentemente tem sido discutida em razão do grande número de escolas formadoras que estão sendo criadas nos últimos anos. Essas escolas têm sido impulsionadas principalmente pelo PROFAE e pelo crescimento do número de serviços de saúde que estão sendo ampliados no país, como as equipes de saúde da família que requerem técnicos de enfermagem na composição de suas equipes básicas para implantação (JÚNIOR, 2008, p. 867).

Um estudo demonstrou que o educar é considerado como um dos papéis que o enfermeiro assume em sua prática profissional, não apenas focado para educação em saúde, mas na formação de novos profissionais, portanto, ensinar é criar possibilidades de produção e construção, e não apenas transmitir conhecimentos e conteúdos, mas levando em consideração a história desse indivíduo. No entanto, o processo de ensino-aprendizagem precisa ser feito de forma em que o docente permita a construção de uma formação esperada pelos discentes, de forma crítica 
quanto a realidade, e com uma prática profissional comprometida com a ética (DUARTE; LUNARDI; BARLEM, 2016).

Para exercer a docência é exigido compromisso moral e social com a educação, pelo fato de as atividades serem desenvolvidas em cursos de formação profissional de indivíduos que desenvolveram ações, ou seja, comprometidos em cuidar de outras pessoas (DUARTE; LUNARDI; BARLEM, 2016).

O enfermeiro docente compromissado com a construção do conhecimento, com vistas à formação de recursos humanos que desenvolverão a prática do cuidado, se percebe, muitas vezes, imerso em um contexto de trabalho com muitas exigências e responsabilidades. Frequentemente se vê, também, pouco instrumentalizado e sem o apoio necessário para implementar estratégias a fim de superar tais situações (DUARTE; LUNARDI; BARLEM, 2016, p.2).

De acordo com a citação acima podemos compreender a necessidade do enfermeiro docente de obter recursos e instrumentos que possam auxiliar na construção de seus conhecimentos.

Nos últimos cinquenta anos a legislação educacional brasileira implementou a LDB por meio de influências tradicionais e liberais, favorecendo para diferentes tendências pedagógicas na formação docente, portanto, uma dessas tendências valoriza a formação de docentes compromissados com pesquisas e na reflexão. A prática e a formação do docente tem sido motivo de debates como forma de obtenção e de melhorias no processo de ensino-aprendizagem, dentro dos programas e educação inicial e continuada (PERES, et al, 2013).

Compreende-se que durante a formação acadêmica já inicia a construção de conhecimentos, quando o docente consegue refletir sobre sua própria formação, não apenas aquela adquirida na sala de aula, mas aquela que é adquirida durante suas leituras, pesquisas, discussões, e na participação de eventos. Nesse instante, o docente está criando e formalização seu repertório de conhecimentos que levará 
durante toda sua vida, com a necessidade de sempre estar aprimorando (SEIXAS; CALABRÓ; SOUSA, 2017).

\section{CONCLUSÃO}

Seguindo a premissa cientifica do estudo buscou-se apresentar a formação do enfermeiro docente, por meio de revisões bibliográficas foi possível alcançar o objetivo inicialmente proposto desse trabalho.

Um ponto de relevância para o estudo foi o fato de observar as transformações ocorridas na formação de enfermeiros docentes durante os últimos anos conforme as citações abordadas no trabalho.

Podemos destacar a necessidade do docente em valorizar a educação inicial e continuada para sua atuação na docência em enfermagem.

Diante do exposto, faz-se a necessidade de repensar na formação de docentes enfermeiros, pois a atuação deles pode ser influenciada diante das necessidades que ocorrem no processo de ensino-aprendizagem.

Faz-se necessário que o docente enfermeiro invista em formação que aborde práticas críticas e reflexivas para que consigo refletir desde sua formação inicial e continuada, na inserção de pesquisas para formação de ações construtivas e críticas.

\section{REFERÊNCIAS}

BACKES, S. D. et al. Repensando o ser enfermeiro docente na perspectiva do pensamento complexo. Revista Brasileira de Enfermagem, v. 63, n. 3, p. 421-26, 2010 .

DUARTE, G. C.; LUNARDI, L. V.; BARLEM, D. L. E. Satisfação e sofrimento no trabalho do enfermeiro docente: uma revisão integrativa. Revista Mineira de Enfermagem, v. 20, p. 1-8, 2016. 
FRIEDLANDER, R. M.; MOREIRA, A. T. M. Formação do enfermeiro: características do professor e o sucesso escolar. Revista Brasileira de Enfermagem, v. 59, n. 1, p. 9-13, 2006.

GERHARDT, E. T.; SILVEIRA, T. D. Métodos de pesquisa. Porto Alegre: Editora da UFRGS, 2009. uni. 3, p. 66.

JÚNIOR, F. A. M. Os reflexos da formação inicial na atuação dos professores enfermeiros. Revista Brasileira de Enfermagem, v. 61, n. 6, p. 866-71, 2008.

MORAES, M. A. C. Enfermeiro educador, enfermeiro professor: formação e práticas educativas. 2004. 65 F. Dissertação (Mestrado em Educação junto ao Programa de Pós-graduação em Educação na área de Ensino Superior) Universidade Católica de Campinas, 2004. Disponível em:

http://tede.bibliotecadigital.puccampinas.edu.br:8080/jspui/bitstream/tede/668/1/Carlos\%20Alberto\%20Martinez\%2 0de\%20Moraes.pdf. Acesso em: 16 out. 2018.

PEREIRA, M. G. L.; CARDOSO, L. A. A formação profissional do enfermeiro docente, que atua no ensino técnico: e o saber formar profissionais capazes de pensar e gestar soluções. Revista Uningá, v. 54, n. 1, p. 79-90, 2017.

PERES, R. G. et al. A formação do docente e desafios da prática reflexiva. Educação Santa Maria, v. 38, n. 21, p. 289-304, 2013.

RODRIGUES, P. T. M.; SOBRINHO, M. C. A. J. O enfermeiro professor e a docência universitária. Revista Brasileira de Enfermagem, v. 59, n. 3, p. 456-9, 2006.

RODRIGUES, J.; MANTOVANI, F. M. O docente de enfermagem e sua apresentação sobre a formação profissional. Revista de Enfermagem, Escola Anna Nery, v. 11, n. 3, p. 494-99, 2007.

SEIXAS, M. H. R.; CALABRÓ, L.; SOUSA, O, D. A formação de professores e os desafios de ensinar ciências. Revista Thema, v. 14, n. 1, p. 289-303, 2017. 
SOUZA, M. D. et al. Preparo pedagógico de enfermeiros docentes para educação profissional técnica de nível médio. Revista Brasileira de Enfermagem, v. 71, n. 5, p. 2577-84, 2018.

Enviado: Maio, 2020.

Aprovado: Junho, 2020. 